\title{
Impact of chronic Immune Thrombocytopenic Purpura (ITP) on health-related quality of life: a conceptual model starting with the patient perspective
}

\author{
Susan D Mathias*1, Sue K Gao ${ }^{2}$, Kimberly L Miller ${ }^{3}$, David Cella ${ }^{4}$, \\ Claire Snyder ${ }^{5}$, Ralph Turner ${ }^{6}$, Albert $\mathrm{Wu}^{5}$, James B Bussel ${ }^{7}$, James N George ${ }^{8}$, \\ Robert McMillan ${ }^{9}$, Diane Kholos Wysocki ${ }^{10}$ and Janet L Nichol ${ }^{2}$
}

\begin{abstract}
Address: ${ }^{1}$ Health Outcomes Solutions, P.O. Box 2343; Winter Park, Florida 32790, USA, ${ }^{2}$ Amgen, Inc., One Amgen Center Drive; Thousand Oaks, CA 91320-1799, USA, ${ }^{3}$ ICON Clinical Research, Lifecycle Sciences Group, 188 Embarcadero, Suite 200; San Francisco, CA 94105, USA, ${ }^{4}$ Evanston Northwestern Healthcare and Northwestern University Medical School, 1001 University Place, Suite 100; Evanston IL 60201, USA, 5John Hopkins University, 624 North Broadway; Baltimore, MD 21205, USA, 'Phase V Technologies, Inc., 20 Walnut Street; Wellesley Hills, MA 02481, USA, ${ }^{7}$ New York Presbyterian Hospital/Weill Cornell Medical Center, 525 East 68th Street; New York, NY 10021, USA, ${ }^{8}$ University of Oklahoma Health Sciences Center, P.O. Box 26901; Oklahoma City, OK 73190, USA, 9The Scripps Research Institute, 10550 N Torrey Pines Road; La Jolla, CA 92037, USA and ${ }^{10}$ University of Nebraska at Kearney, Copeland Hall 120B; Kearney, NE 68849, USA
\end{abstract}

Email: Susan D Mathias* - smathias@healthoutcomessolutions.com; Sue K Gao - sgao@amgen.com; Kimberly L Miller - kmiller@ovation.org; David Cella -d-cella@northwestern.edu; Claire Snyder - csnyder@jhsph.edu; Ralph Turner - faze5rt@msn.com; Albert Wu - awu@jhsph.edu; James B Bussel - jbussel@med.cornell.edu; James N George - james-george@ouhsc.edu; Robert McMillan - mcmillan@scripps.edu; Diane Kholos Wysocki - wysockid@unk.edu; Janet L Nichol - nicholjl@roadrunner.com

* Corresponding author

Published: 8 February 2008

Health and Quality of Life Outcomes 2008, 6:13 doi:10.1186/1477-7525-6-13
Received: 25 October 2007

Accepted: 8 February 2008

This article is available from: http://www.hqlo.com/content/6/1//3

(C) 2008 Mathias et al; licensee BioMed Central Ltd.

This is an Open Access article distributed under the terms of the Creative Commons Attribution License (http://creativecommons.org/licenses/by/2.0), which permits unrestricted use, distribution, and reproduction in any medium, provided the original work is properly cited.

\begin{abstract}
Background: Immune thrombocytopenic purpura (ITP), a condition characterized by autoimmune-mediated platelet destruction and suboptimal platelet production, is associated with symptoms such as bruising, epistaxis, menorrhagia, mucosal bleeding from the gastrointestinal and urinary tracts and, rarely central nervous system bleeding. The aim of this research is to develop a conceptual model to describe the impact of ITP and its treatment on patients' health-related quality of life (HRQoL).
\end{abstract}

Methods: A literature search and focus groups with adult ITP patients were conducted to identify areas of HRQoL affected by ITP. Published literature was reviewed to identify key HRQoL issues and existing questionnaires used to assess HRQoL. Focus group transcripts were reviewed, and common themes were extracted by grouping conceptual categories that described the impact on HRQoL.

Results: The literature synthesis and themes from the focus group data suggest that decreased platelet counts, disease symptoms, and treatment side effects influence multiple domains of HRQoL for ITP patients. Key areas affected by ITP and its treatments include emotional and functional health, work life, social and leisure activities, and reproductive health.

Conclusion: ITP affects various areas of HRQoL. This conceptual model will help inform the evaluation of therapeutic strategies for ITP. 


\section{Background}

Immune thrombocytopenic purpura (ITP) is an autoimmune disorder characterized by accelerated platelet destruction and suboptimal platelet production that leads to reduced peripheral blood platelet counts [1-3]. The etiology of ITP is poorly understood [4]. The estimated annual incidence of adult ITP ranges from 0.6 to 6.6 cases per 100,000 adults [1,4-6]. Women are affected disproportionately, with a female to male ratio of nearly two to one [1]. ITP in adults infrequently remits spontaneously [1] and, although the course of the disease is unpredictable, ITP is rarely fatal, if appropriately managed [4,7].

The physical signs and symptoms of ITP can vary by patient. Some patients suffer from major bleeding that requires immediate attention [8], while other patients with ITP present with few symptoms apart from an increased tendency to bruise or have mucosal bleeding. The degree of bleeding throughout the course of the disease is largely dependent on the patient's platelet count, although other factors certainly contribute. Those with the lowest platelet counts are at the greatest risk for bleeding which can include menorrhagia, gastrointestinal or urinary tracts bleeding and, in rare cases, central nervous system or intracranial bleeding [8]. ITP patients with persistently very low platelet counts $\left(<10 \times 10^{9} / \mathrm{L}\right)$ despite treatment, are at risk for both fatal and non-fatal bleeding events [9]. Specifically, Cohen, et al. estimated that fiveyear mortality rates for ITP patients with persistent low platelet counts $\left(<30 \times 10^{9} / \mathrm{L}\right)$ ranged from $2.2 \%$ for patients under 40 years of age and $47.8 \%$ for patients older than 60 [7].

Treatments currently approved for use in ITP include corticosteroids, intravenous immunoglobulins (IVIG), antiD immunoglobulins, splenectomy, rituximab, and cyclophosphamide $[1,2,10,11]$. Standard first line therapy for those with low platelet counts consists of medications such as oral corticosteroids and intravenous immunoglobulins. Patients who do not respond to medical therapies, who relapse after response to therapies, or who require potentially intolerable doses of medical therapies to achieve platelet counts high enough to prevent bleeding usually undergo splenectomy, if the patient is a suitable candidate [11]. Patients who do not respond to or relapse after splenectomy may be treated with a wide spectrum of treatments including corticosteroids, rituximab, danazol, immunosuppressants (e.g. cyclosporine or mycophenolate mofitil) or cytotoxic agents (e.g. cyclophosphamide or azathioprine), each with their own side effects $[1,2,4,8]$. These treatments have variable effectiveness in treating ITP, and may often be associated with substantial side effects [4]. The one year incidence of diabetes, obesity, and gastrointestinal bleeds are two times higher, and the one year incidences of myocardial infarction and oste- oporosis are three times higher in ITP patients receiving treatment with corticosteroids than age- and gendermatched non-ITP patients [12].

Although splenectomy results in long-term disease control in about two-thirds of patients, the long-term outcome in the individual patient is unpredictable [13]. Further, splenectomy patients are at a slightly increased risk for overwhelming sepsis [13]. Currently approved medical treatments for ITP can cause major adverse reactions [14]. For instance, rituximab infusions may cause chills, fever, or severe anaphylactoid reactions [2]; danazol is associated with rash, masculinizing symptoms and liver toxicity [1]; cytotoxic agents may cause cytopenias, gastrointestinal symptoms and, rarely secondary malignancies [8]; and immunosuppressive agents can subject the patient to increased risk of infection [1]. Patients and physicians need to consider both the impact of symptoms of ITP as well as the impact of treatment side effects when making decisions about treatment. It is, therefore, important to incorporate the patient's perspective in decisions regarding the management of their ITP.

Patient-reported outcomes (PROs) provide information from the patient's perspective. PROs have become important tools for understanding the effects of both disease and treatments for various diseases. Health-related quality of life (HRQOL) is the most commonly assessed PRO in clinical research. Both the US Food and Drug Administration (FDA) and the European Agency for the Evaluation of Medicinal Products (EMEA) have emphasized the value of PRO measures in identifying and quantifying the impact of a disease or its treatments on daily life, physical, psychological and social functioning, and well-being $[15,16]$. Further, these agencies have recently indicated that developing an appropriate and clearly defined conceptual model is a critical step in the development and use of PRO measures $[15,16]$.

In an earlier paper, Mathias, et al. presented the development and validation of an instrument, the ITP-Patient Assessment Questionnaire (ITP-PAQ), to assess HRQoL in ITP patients $[17,18]$. However, the conceptual model linking the biological and physiological variables of ITP to HRQoL was not included. The aim of this research is to develop a conceptual model to describe the impact of ITP and its treatment on patients' HRQoL.

\section{Methods}

This project uses the model proposed by Wilson and Cleary [19] as a guide for illustrating how biologic and physiologic variables can lead to changes in general health perceptions and overall HRQoL in patients with ITP. Two data sources were used: existing literature and patient contribution. Two literature searches were conducted to iden- 
tify existing research that gathered information directly from ITP patients regarding their disease or treatment. Also, focus groups were held to solicit patients' input. The focus group format allowed for dynamic responses that built upon the contributions of each patient. Both data sources were referenced in developing a comprehensive conceptual model for HRQoL in adult ITP patients.

\section{Literature review}

The purpose of the literature reviews was to summarize relevant issues for ITP patients, identify existing HRQOL questionnaires used with ITP patients, describe the clinical aspects of chronic ITP, and describe the impact of ITP and its treatments on patients' HRQoL. Search terms in MEDLINE between the years 1997 and 2007 included "idiopathic thrombocytopenic purpura," "immune thrombocytopenic purpura" or "ITP" and "outcomes," "well being," "quality of life," or "questionnaire". The searches were limited to adults ( $>18$ years old). Although, a literature search was conducted at the time of the focus groups in 2001, a supplemental search was conducted now to capture more recent work.

Published abstracts were reviewed to identify those that focused on the effect of ITP or ITP treatments. In addition, new PRO questionnaires that were developed after 2001, one of which was the outcome of the focus group interviews employed here, were reviewed for relevance. Research reports that did not focus solely on ITP, e.g. studies on general hematologic disorders, were excluded from the review. All remaining publications were retrieved and reviewed to identify aspects that affect HRQoL, including symptoms of the disease and side effects of treatments.

\section{Focus groups}

Patients

In June 2001, moderated traditional (in-person) focus groups were conducted in New York City, NY (NY), Oklahoma City, OK (OK), and San Diego, CA (CA) to identify the important issue areas for ITP patients. The information from these focus groups was initially used to develop the ITP-Patient Assessment Questionnaire (ITP-PAQ), an ITP-specific HRQoL questionnaire that has since been validated $[17,18]$. For each focus group, patients were recruited at a local academic-based tertiary care center. The study protocol was prepared and approved by a central Institutional Review Board, and all patients provided written informed consent to participate. Patients were eligible if they were at least 18 years old, had active ITP, and were willing to participate in the focus group. Although there were no specific clinical or medical history requirements for participation in the focus groups, clinicians at each site invited patients who had active disease and required treatment and/or frequent monitoring. Each focus group consisted of 7 or 8 patients, with at least one male patient in each group. A trained moderator used a semi-structured interview format to direct the discussion, encourage interaction among members of the focus group, and ask clarifying questions. The focus groups lasted between 2-3 hours and were audio taped and transcribed. Participants were provided with an honorarium for their time.

\section{Data analysis}

A project team member divided the transcripts from each focus group into individual units of text. The text units were segments of continuous speech ranging in size from phrases to entire paragraphs that referred to some effect of ITP on the individual's life. No analytic software was used for the qualitative analysis.

Although each focus group was transcribed verbatim, the transcription method was not standardized across focus group location. For instance, each time a focus group participant spoke during the $\mathrm{OK}$ and $\mathrm{CA}$ focus groups, the transcriber identified the participant by a patient identifier. However, none of the NY participants were similarly identified. Therefore, when evaluating the frequency with which individual patients reported a specific theme, only the OK and CA responses were considered. For the NY focus group responses it was simply assessed whether or not patient(s) in the focus group reported the concept.

Each text unit was given equal weight, except in instances where the same patient reported the same concept during the CA and OK focus groups. In such cases, the text units were grouped and counted only once per patient. After the text units were identified and - when possible - categorized by patient, a second project team member grouped the text units into sub-categories by clustering groups of identical text units, or ones that addressed essentially the same concept. The sub-categories were then grouped into primary conceptual categories. A grid was developed to schematically identify common factors among the themes.

\section{Conceptual model}

Although ideally, the development of a conceptual model would precede the development of a questionnaire, in this instance the activities were not carried out in that sequence. The focus groups and literature review that were conducted in 2001 were used for item generation in the development of the ITP-PAQ in the absence of a conceptual model [17]. We used the focus groups and an updated literature review to develop the structure and content of the conceptual model, in an approach similar to the one described as simultaneous concept development by Finfgeld-Connett [20]. The simultaneous concept development approach assumes that the elements of the conceptual model are likely to be closely linked and the 
relationships should be considered in developing the model.

The common themes identified in the information from the literature and text units from the focus groups drove the formation of the initial conceptual model. The relationship between the sub-categories and primary conceptual categories were based on the patient attributions. The initial conceptual model was submitted for review at a consensus group meeting where the research team and expert consultants and clinicians reviewed the categories and the proposed relationships to refine the interrelationships among the categories. The categories and relationships were then organized into a final conceptual model representing the impact of ITP on HRQoL.

\section{Results}

\section{Literature review}

The current literature search identified 72 articles of which thirty-three citations were excluded because ITP was not an inclusion criterion for the presented research. Figure 1 describes the categorization of the search results. As illustrated in the figure, most of the articles reviewed focused on the outcomes associated with treatment including comparisons between multiple types of treatments (including corticosteroids) [21,22], open or laparoscopic splenectomy [23-31], intravenous anti-D immunoglobulin [32,33], rituximab [14], intravenous immunoglobulin (IVIg) [34], etanercept [35], combination chemotherapy regimens [36], or summary reviews of treatments [37-40]. The remaining articles pertained to a variety of aspects related to ITP, including pregnancy outcomes [41-47], country-specific retrospective chart reviews [48-51], or literature reviews [13,52-54].

The physical manifestation, the risks, and the clinical aspects of the disease are well characterized in the literature. Some studies mentioned the specific physical signs and symptoms of ITP, such as bleeding and bruising $[21,54,55]$. The degree, frequency, or severity of bleeding

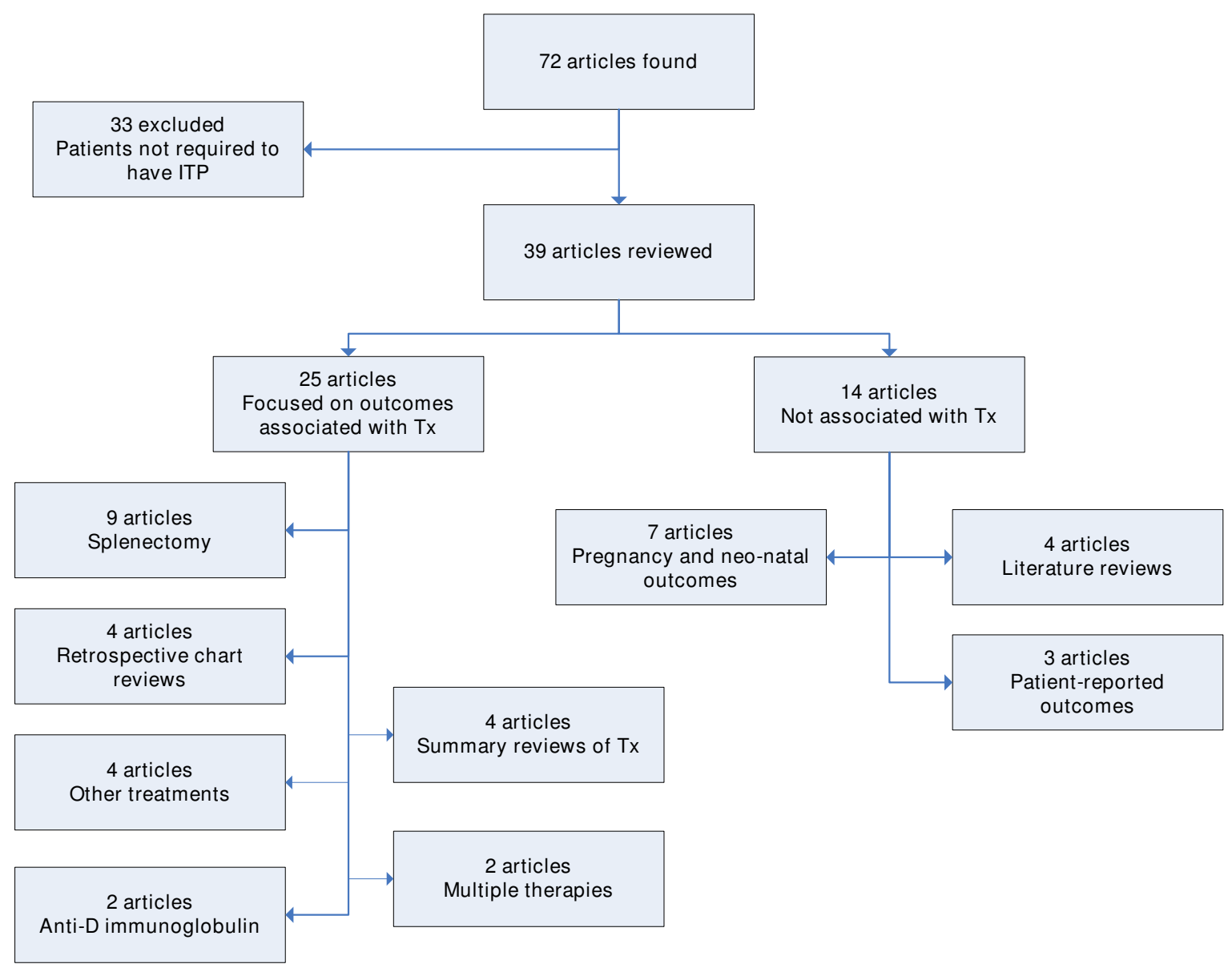

Figure I

ITP HRQoL literature review flowchart. 
and bruising as a measured outcome of treatment was often reported [25,32,41-43,48,53]. However, the literature search yielded few research reports that collected data directly from the patients or that described the impact of disease on the patients' HRQoL. We describe each study identified in the literature search that incorporated PRO data in characterizing ITP.

In a 2002 study of 28 ITP patients receiving repeated infusions of anti-D, Cooper, et al. asked patients to complete a study-specific six-item questionnaire to assess whether there was a change in HRQoL from the baseline assessment [32]. The six questions included one item on each of the following concepts: well-being compared to baseline, general health compared to the previous year, interference of physical or emotional problems with social activities, and three items related to energy including how often the patient "has a lot of energy", "feels full of pep", and "feels tired". At the 6-month follow-up assessment, patients reported a decrease in well-being compared to their baseline response. At the 12 and 18-month follow-up assessments, patients reported an improvement in general health compared to the previous year, and a reduction in the interference of physical or emotional problems with social activities. There were no significant changes over time in the more specific questions about energy level.

The search also yielded a few articles that focused primarily on the use of patient questionnaires. In 2007, Matzdorff and Arnold surveyed 91 patients with ITP in Germany [55] to determine whether they had been treated according to the 1996 ASH guidelines. Through the survey, the researchers assessed personal and disease history, treatment history, and informational and decision-making history. The most common treatment patients received was corticosteroids (94\%), followed by IV Ig (56\%). Seventy-five percent of the patients reported experiencing some side effects from corticosteroid treatment, including weight gain (58\%), moon face (48\%), depression and anxiety (35\%), and restlessness and insomnia $(22 \%)$.

In another study Cohen, et al. modeled quality-adjusted life expectancy in ITP. They made assumptions regarding utility values based on the age- and sex-adjusted Quality of Well Being Index utility values reported for other patient populations, because values were not available for ITP patients. Cohen, et al. predicted that a 30-year old woman remaining thrombocytopenic due to ITP would lose 20.4 years (14.9 quality-adjusted life years) of her potential life expectancy [7].

Zhou, et al. used the Medical Outcomes Study Short Form 36 Health Survey (SF-36) to measure HRQoL in 236 adults with ITP in a cross-sectional study [56]. In addition to the SF-36, a study questionnaire asked patients to rate their fear of bleeding on a 4-point likert scale. Most of the patients $(88.1 \%)$ reported some fear of bleeding. The authors found that this fear had a significant detrimental impact on SF-36 scores. They also found that patients who had been diagnosed with ITP more than 6 months ago had lower HRQoL than patients diagnosed less than 6 months ago.

Mathias, et al. reported on the development and psychometric validation of the 44 item ITP-PAQ to measure HRQoL [17]. The ITP-PAQ was developed based on findings from the published literature, existing questionnaires, expert clinical opinion from leading hematologists, and input from focus groups of ITP patients. The final questionnaire contains 10 scales, including Symptoms, Bother-Physical Health, Fatigue/ Sleep, Activity, Fear, Psychological Health, Work, Social Activity, Women's Reproductive Health, and Overall QOL.

Recently, McMillan, et al. reported on the comparison of SF-36 scores of ITP patients with SF-36 scores of the general US population and the scores of patients with hypertension, arthritis, diabetes mellitus, congestive heart failure, missing or paralyzed limb, or cancer [57]. These authors found significantly lower scores in patients with ITP compared to the general US population for nearly all the SF-36 domains (except mental health). They also found that the physical impact of chronic ITP on HRQoL was similar to that of diabetes and greater than that of hypertension, arthritis, or cancer. They acknowledge that distinguishing whether ITP or the treatment of ITP contributes to the reduction of HRQoL can be challenging, especially with a generic instrument like the SF-36.

\section{Focus groups}

Twenty-three patients (OK:8, CA:7, NY:8) participated in the focus groups, 16 (70\%) were women (OK:5, CA:6, NY:5). No additional demographic data were collected. Focus group data used to shape the conceptual model are summarized in Tables 1 and 2. Table 1 contains the comprehensive list of themes reported by the patients. Each theme is grouped into a primary conceptual category (ag). Table 2 indicates the emphasis given to each primary conceptual category during the focus group discussions. Not surprisingly, based on the patients' attributions (a) symptoms, e.g., bleeding and bruising, that result from low platelet counts; and, (b) side effects of treatment, e.g., weight gain and mood swings, were mentioned as significant impairments to overall HRQoL. These two categories were considered the main determinants of HRQoL changes for patients with ITP. 
Table I: Comprehensive list of themes

\begin{tabular}{|c|c|}
\hline a. Signs and Symptoms & c. Emotional Health \\
\hline Fatigue & Relationships \\
\hline - Inability to get out of bed & - Spouse \\
\hline - Limits daily activities & - Family \\
\hline Bleeding & - Friends \\
\hline - Blood blisters & - Children \\
\hline - Bleeding from gums & Fear, Stress, \& Anxiety \\
\hline - Nose bleeds & - Fear of accidents \\
\hline - Embarrassment & - Fear of intracranial bleeding \\
\hline Bruising & - Fear of low platelet counts \\
\hline - Bruises that never go away & - Fear of dying \\
\hline - Bruises all over legs & - Financial stress \\
\hline - Petechia & - Stress contributes to low platelet levels \\
\hline Other & - Anxiety about low platelet levels \\
\hline - Migraines & - Anxiety medical profession's lack of knowledge \\
\hline - Visual impairment & Depression, Isolation, oss of Control \\
\hline \multirow[t]{2}{*}{ - Joint aches } & Seek therapy or counseling \\
\hline & - Suicidal \\
\hline b. Treatment Effects & - Go off by myself \\
\hline Steroids & - Feels alone \\
\hline - Mood swings & - Family/friends don't understand ITP \\
\hline - Weight gain & - Resentment towards health professionals \\
\hline - Anger & - Feels pressure to be strong \\
\hline - Anxiety & Mood \& Self-Conscious \\
\hline - Trouble sleeping/insomnia & - Mood swings \\
\hline - Round face & - Choice of clothing limited due to bruising \\
\hline - Lump in back & - Bothered by needle marks \\
\hline Other treatments & - Avoid mirrors \\
\hline - Headaches & - Embarrassed by bleeding \\
\hline - Hair loss & - Self-conscious about bruising \\
\hline \multicolumn{2}{|l|}{ - More susceptible to colds and fungal infections } \\
\hline & f. Social and Leisure Activities \\
\hline d. Functional Health & Sports/exercise/physical activities \\
\hline Daily Activities & - Unable to go to the gym \\
\hline - Housework, including cooking & - Unable to do sports, boxing, martial arts, skydiving, climbing, dancing \\
\hline - Fatigue limits daily activities & Leisure activities \\
\hline - Extreme care in doing simple tasks & - Unable or too tired to go out with friends \\
\hline Changes in Lifestyle & Travel is limited or more difficult \\
\hline - Inability to plan for the future & Feelings of isolation due to physical and emotional effects of ITP \\
\hline - Reduction in risk-taking activities & Social stigma \\
\hline - Hide the severity of disease from family & - People suspect spousal or parental abuse due to bruising \\
\hline \multicolumn{2}{|l|}{ Sleep } \\
\hline - Restlessness & g. Reproductive Health \\
\hline - Not comfortable & Women's Reproductive Issues \\
\hline \multirow[t]{2}{*}{ - Tired, but unable to sleep } & - Hysterectomy because of bleeding \\
\hline & - Heavy menstrual bleeding \\
\hline e. Work Life & - Inability to have children \\
\hline Absences & Sex \\
\hline - Permanent disability & - Bruising \\
\hline - Frequent absences due to illness, and due to medical visits & - Bleeding \\
\hline - Unemployed & - Reduced libido \\
\hline \multicolumn{2}{|l|}{ Change in Attitudes } \\
\hline \multicolumn{2}{|l|}{ - Work to support family } \\
\hline \multicolumn{2}{|l|}{ - Work in a low risk environment } \\
\hline \multicolumn{2}{|l|}{ - Work is a lower priority } \\
\hline \multicolumn{2}{|l|}{ - Work is not as satisfying } \\
\hline \multicolumn{2}{|l|}{ Productivity } \\
\hline \multicolumn{2}{|l|}{ - Fatigue hinders work } \\
\hline \multicolumn{2}{|l|}{ - Working part-time due to absences } \\
\hline \multicolumn{2}{|l|}{ Career advancement } \\
\hline \multicolumn{2}{|l|}{ - Lost promotions } \\
\hline \multicolumn{2}{|l|}{ - Unable to pursue desired career } \\
\hline - Change career & \\
\hline
\end{tabular}


Table 2: Frequency of Reports of Primary Conceptual Categories and Sub-Categories from ITP Focus Groups

\begin{tabular}{|c|c|c|c|c|c|}
\hline & OK & NY & CA & & $\mathbf{N}=\mid \mathbf{5}(\%)^{*}$ \\
\hline a. Signs and Symptoms & & & & 14 (93\%) & \\
\hline Fatigue & + & - & + & & $14(93)$ \\
\hline Bleeding & + & + & + & & $8(53)$ \\
\hline Bruising & + & + & + & & $8(53)$ \\
\hline Other & + & + & + & & $8(53)$ \\
\hline b. Treatment Effects & & & & $13(87)$ & \\
\hline Steroids & + & + & + & & $13(87)$ \\
\hline Other treatments & + & + & + & & $8(53)$ \\
\hline c. Emotional Health & & & & 14 (93) & \\
\hline Fear, stress \& anxiety & + & + & + & & II (73) \\
\hline Relationships & + & + & + & & $7(47)$ \\
\hline Depression, isolation, \& loss of control & + & + & + & & $7(47)$ \\
\hline Mood \& self-consciousness & + & + & + & & $7(47)$ \\
\hline d. Functional Health & & & & $13(87)$ & \\
\hline Daily activities & + & + & + & & II (73) \\
\hline Sleep & + & + & + & & $9(60)$ \\
\hline Changes in lifestyle & + & + & + & & $7(47)$ \\
\hline e. Work & & & & $13(87)$ & \\
\hline Absences & + & + & + & & $10(67)$ \\
\hline Changes in attitudes & - & + & + & & $5(33)$ \\
\hline Career advancement & + & + & + & & $3(33)$ \\
\hline Productivity & + & + & + & & $4(27)$ \\
\hline f. Social and Leisure & & & & $10(67)$ & \\
\hline Sports/exercise/physical activity & + & + & + & & $5(33)$ \\
\hline Leisure activities & + & + & + & & $5(33)$ \\
\hline Social Stigma & + & - & + & & $4(27)$ \\
\hline Travel & + & + & + & & $3(20)$ \\
\hline g. Reproductive Health & & & & $10(67)$ & \\
\hline Sex & + & + & + & & $9(60)$ \\
\hline Women's reproductive issues & + & + & + & & $8(53)$ \\
\hline
\end{tabular}

\footnotetext{
$+=$ theme present in focus group

- = theme not present in focus group

* based on data from OK and CA focus groups only
}

Also, Table 2 provides details about the sub-categories included in each of the primary conceptual categories. The table indicates whether the sub-category was mentioned during each of the focus groups and provides the number (and percentage) of patients that mentioned the sub-categories in the CA and OK focus groups. Although most subcategories were mentioned during all focus groups, a few differences emerged which are highlighted below.

\section{Conceptual model}

Based on the findings from the literature review and focus groups, we developed a conceptual model as presented in Figure 2. Following the Wilson \& Cleary model [19], the biologic variable (platelet count) and the main determinants (signs and symptoms of ITP and the treatment effects) were placed on the left side of the causal model. This was followed by the domains of emotional and functional health, work life, social and leisure activities, and reproductive health. This model proposes that symptoms of ITP and side effects of its treatment lead to a worsening in HRQoL by adversely affecting certain domains. Below we discuss each component of the model.

\section{Biological variables}

Platelet counts, with or without the presence of any signs or symptoms, are often the only determinant of treatment decisions $[54,58]$ and are also used to establish whether the patient has responded to treatment and whether the response is considered complete, partial, or minimal [54]. Platelet counts are inversely correlated with bleeding outcomes, and are of utmost concern to patients. Patients that had undergone splenectomy emphasized that generally their platelet counts rose immediately following the procedure, but then the platelet counts leveled off or dropped in the months and years post-surgery. The potential for and actual drops in platelet counts may cause emotional distress. Some patients report that it is "like a rollercoaster" or that their platelet levels "go way up and then way down". Table 3 contains further examples of verbatim patient quotes on platelet counts and other discussion areas from the focus group participants. 


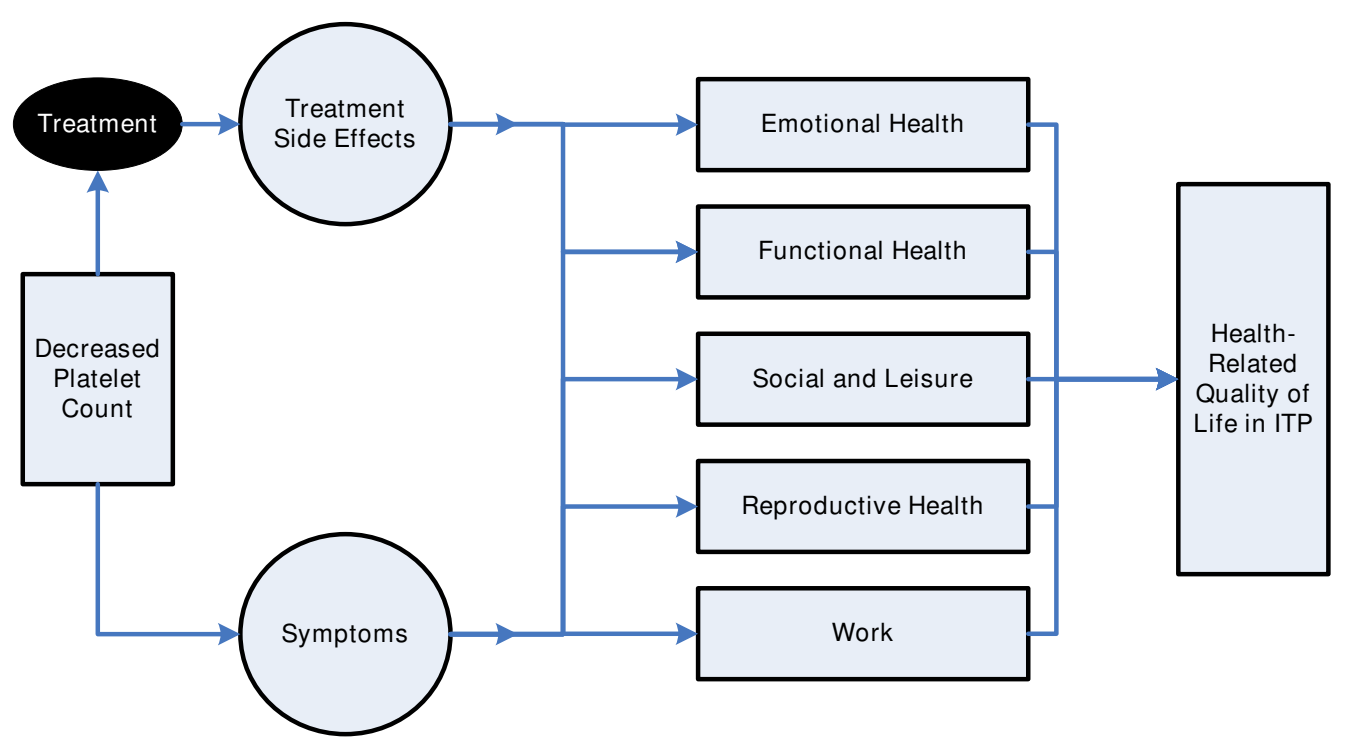

\section{Figure 2}

Conceptual model for HRQoL in patients with ITP.

The focus group comments regarding the unease associated with platelet counts support Zhou, et al.'s assessment that the fear of bleeding due to low platelet counts may itself interfere with patients' HRQOL [56].

\section{Main determinants}

Signs and Symptoms

Table 2a indicates the most commonly reported signs and symptoms that patients attributed to ITP. One patient in the CA focus group characterized fatigue as follows, "Fatigue is [the] number one [issue] for me." Moreover, as shown in Table $2 \mathrm{a}$, fatigue was reported by over $90 \%$ of the patients in the CA and OK focus groups. Interestingly, fatigue was not mentioned in the NY focus group.

Other very commonly reported symptoms were bleeding and bruising. In describing her bleeding, one patient said "I guess the worst was probably ... when I had a lot of bleeding in my mouth. I hate when I taste blood." Another patient described her bruising by stating, "I'm bruised all the time and I'm pretty used to it now. It's very annoying, but it's just a way of life now."

Although they did not provide details or rationale for the selection of the items, Cooper, et al.'s choice of questions suggests that fatigue was a primary concern for ITP patients [32]. Other reports in the literature suggest that anemia, a likely cause of fatigue, is common in ITP patients, especially in the presence of bleeding [48]. In particular, Cines and Bussel provide anecdotal evidence of a young female patient experiencing extreme fatigue at platelet counts $<50,000 \times 10^{9} / \mathrm{L}$ [59].

\section{Treatment Effects}

Table $2 \mathrm{~b}$ indicates that the most commonly reported adverse effects of ITP treatment were attributed to the use of steroids. The focus group patients reported numerous effects of corticosteroid treatment, including anger, insomnia, mood swings, and weight gain (see Table 1 for more detail). Most patients in the CA and OK focus groups reported that the adverse effects of steroids negatively impacted their lives. One patient summarized her feelings about steroids by stating, "I won't take it and my count is 3 and I won't take it because my quality of life means too much and I already don't feel good." Some patients also expressed increased concern over susceptibility to infection as a result of splenectomy. For instance, a female patient in the CA focus group stated "I'm very susceptible to illness, colds, and lung problems. I've become fanatical with germs. I don't touch things." Patients also articulated some concern about the decision to proceed with a splenectomy when remission following splenectomy is far from certain. Similar observations were reported in the findings of Matzdorff and Arnold [55].

\section{HRQoL domains}

Emotional Health

Patients frequently mentioned "anxiety", "depression", and "fear" to describe their feelings about their symptoms. Many patients reported that ITP and its symptoms had an effect on their personal relationships. Table $2 c$ shows that 
Table 3: Direct quotes from ITP patient focus groups

\begin{tabular}{|c|c|}
\hline Biological Variables & $\begin{array}{l}\text {-"like a rollercoaster" } \\
\text {-" [platelet levels] go way up and then way down" } \\
\text { - "[The fact that] you're sick now but you'll be okay in } 2 \text { days or } 2 \text { weeks... was a particularly difficult area for me to } \\
\text { handle." } \\
\text { - "[After splenectomy] my platelet count went up to } 500,000 \text { right after splenectomy, a month later it was back down } \\
\text { to the teens." }\end{array}$ \\
\hline \multicolumn{2}{|l|}{ Main Determinants } \\
\hline Signs \& Symptoms & $\begin{array}{l}\text { - "Fatigue is [the] number one [issue] for me." } \\
\text { - "I guess the worst was probably ... when I had a lot of bleeding in my mouth. I hate when I taste blood." } \\
\text { - "I'm bruised all the time and I'm pretty used to it now. It's very annoying, but it's just a way of life now." } \\
\text { - "I've had about three really heavy duty nosebleeds lasting several days and you just have to immobilize yourself and } \\
\text { hope that the clot will finally hold." } \\
\text { - "I get bruises now and then. I do have petechia most of the time on my legs" }\end{array}$ \\
\hline Treatment Effects & $\begin{array}{l}\text { - "I won't take it [steroids] and my count is } 3 \text { and I won't take it because my quality of life means too much and I } \\
\text { already don't feel good." } \\
\text { - "I'm very susceptible to illness, colds, and lung problems. I've become fanatical with germs. I don't touch things." } \\
\text { - "It's like rocket fuel. All of you know who've done steroids, it's terrible stuff. I think steroids are the worst. steroids } \\
\text { were worse than the chemo drugs were." } \\
\text { - "If I would have heard } 50 / 50 \text { [chance of success/failure] I wouldn't have done it. That } 70 / 30 \text { sounded really good to } \\
\text { me." }\end{array}$ \\
\hline \multicolumn{2}{|l|}{ HRQoL Domains } \\
\hline Emotional Health & $\begin{array}{l}\text { - "The thing about families is they look at you and expect to see you being strong. I feel like they expect me to be able } \\
\text { to deal with this." } \\
\text { - "The worst part about it is the emotional strain that was put on everyone around me." } \\
\text { - "There [are] times that I won't go to the doctor because I know that I can't afford to go." } \\
\text { - "I have that fear [of accidents]. I always make the sign of the cross because I know if I get banged up I'm gonna bleed." } \\
\text { - "When you're in a flare you just feel off in a corner by yourself and you're isolated from everyone." }\end{array}$ \\
\hline Functional Health & $\begin{array}{l}\text { - "I get so tired I can't even move." } \\
\text { - "I never sleep through the night. It's just restlessness and you're not comfortable." } \\
\text { "You're limited. You don't do what you used to do to the same degree and you'd still like to do that but you can't do } \\
\text { it." "When cooking...you have to be very careful. You have to really take your time when you're cutting." }\end{array}$ \\
\hline Work Life & $\begin{array}{l}\text { - "I loved working but the fact that I have to sleep when I'm not working makes me want to work less so that I can do } \\
\text { something besides sleep." } \\
\text { - "Now I'm a technical writer, which has no [bleeding] risk at all. I just sit at the computer and type. I really don't like } \\
\text { it, but I don't have too many options." } \\
\text { - "I had to take off a lot to go to the hospital to get the treatment." } \\
\text { - "I wanted to be a nurse but I couldn't because I had ITP." } \\
\text { - "Working part-time." }\end{array}$ \\
\hline Social \& Leisure Activities & $\begin{array}{l}\text { - "My friends think I'm crazy because I won't go the movies with them on a Friday night. I'm just so exhausted when I } \\
\text { get home. I don't have the energy to get dressed and go to a movie." } \\
\text { - "My bruising bothers me especially in the summertime when I can't [go swimming] because I'm always bruising and } \\
\text { people look at you funny." } \\
\text { - "I've had co-workers and friends ask me if my husband was beating me." } \\
\text { - "When you're bruising, especially during the summer, and you have to go outside and you're so self conscious } \\
\text { because you know what people are thinking because they automatically just assume, oh boy she's been beat." } \\
\text { - "Well, I find myself more reluctant about meeting new people because I have so many bruises so often." } \\
\text { - "I don't go jumping off planes. I don't even want to swim in the water. I just don't want to get hurt. I'm very fragile } \\
\text { now." } \\
\text { - "I said, Don't look at me to go anywhere. I'm not leaving New York." } \\
\text { - "I always take out traveler's insurance now for cancellations." } \\
\text { - "We used to do extensive traveling and we've limited that down to a week or less at a time any more and we don't } \\
\text { do as many of them as we used to." } \\
\text { - "With my grandchildren, they want to jump on me. They want to do a lot of things. I want to do a lot of things with } \\
\text { them. My daughter tells them 'Don't jump on Grandma. Don't pull her hair. Be careful.' That really bothers me." }\end{array}$ \\
\hline Reproductive Health & $\begin{array}{l}\text { - "When I first got ITP I thought that I couldn't have children. And then my gynecologist told me that I could have } \\
\text { children while taking prednisone. All those years my hematologist made me think I couldn't have children." } \\
\text { - "You have to be cautious...If I had sexual relations [I was afraid] something was gonna happen to me." } \\
\text { - "I don't feel sexy. I don't know if it's the weight gain or if it's the stigma of being sick." } \\
\text { - "When my platelets are low I say "Stay away." [regarding sex]" } \\
\text { - "Much heavier [periods] and lasted anywhere from } 6 \text { to } 9 \text { weeks" } \\
\text { - "Now on the prednisone my desire has went [sic] down considerably. I swear I used to be sexually active } 4 \text { or } 5 \\
\text { nights a week, now it's once or twice a month." }\end{array}$ \\
\hline
\end{tabular}


emotional health concerns were an issue discussed in all focus groups, with a similar number of patients expressing concern over relationships, mental health, and self-consciousness. The emotional concerns appeared to affect women differently than men. Men were particularly concerned with their ability to provide for their families and their need to appear stoic. In contrast, women discussed the protective nature of family and friends and the effect their illness had on others. This is illustrated by a male participant in the OK focus group commenting, "The thing about families is they look at you and expect to see you being strong. I feel like they expect me to be able to deal with this." A female participant in the same focus group stated, "The worst part about it is the emotional strain that was put on everyone around me." The financial strain triggered by the medical expenses also creates a stressful environment for many patients. One patient stated, "There [are] times that I won't go to the doctor because I know that I can't afford to go."

\section{Functional health}

Patients reported a strong relationship between the symptoms of ITP and functional health limitations particularly with respect to the need to limit daily activities (see Table 2d). For instance, patients reported that their activities were limited because of fatigue. "I get so tired I can't even move." or "When I've been on my legs too long, they start cramping" were just two of the comments made by focus group participants. Difficulty sleeping was also reported by many focus group patients, with one patient stating, "I never sleep through the night. It's just restlessness and you're not comfortable."

\section{Work life}

As indicated in Table 2e, the majority of the patients in the focus groups indicated that ITP had interfered with their ability to work, and some individuals mentioned that ITP had hindered their ability to advance in their career. Many patients reported that they took time off or quit working entirely due to the symptoms or treatment of ITP. A female patient stated, "I loved working but the fact that I have to sleep when I'm not working makes me want to work less so that I can do something besides sleep." Patients in CA and NY reported that they had experienced a change in their desire or reason for going to work. For instance, one patient stated, "Now I'm a technical writer, which has no [bleeding] risk at all. I just sit at the computer and type. I really don't like it, but I don't have too many options." However, no patients in the OK focus groups mentioned a change in attitude toward work or work environments.

\section{Social and leisure activities}

Table $2 \mathrm{f}$ shows that patients with ITP report suffering from feelings of social embarrassment due to visible signs of the disease (bruising) and that their involvement in sports or other physical activities is limited. Testimony such as "My bruising bothers me especially in the summertime when I can't [go swimming] because I' $m$ always bruising and people look at you funny" and "I've had co-workers and friends ask me if my husband was beating me" were recorded. Patients also reported that symptoms of ITP prevent them from participating in leisure activities such as exercise, gardening, and travel. A female patient commented, "My friends think I'm crazy because I won't go [to] the movies with them on a Friday night. I'm just so exhausted when I get home. I don't have the energy to get dressed and go to a movie."

\section{Reproductive health}

Both male and female participants in the focus groups reported decreased libido due to the symptoms of ITP and the side effects of treatment. A male participant stated, "Now on the prednisone my desire has gone down considerably. I swear I used to be sexually active 4 or 5 nights a week, now it's once or twice a month." Female participants also reported bruising and bleeding as a result of sexual intercourse.

The numerous publications dealing with pregnancy and obstetrics indicate that ITP greatly affects women, particularly with respect to child bearing. Information from the focus groups highlighted the exacerbation of menstrual bleeding (both severity and duration) in women with ITP. In addition, some women also mentioned anxiety over the potential inability to bear children. However, the literature suggests that the outcome of pregnancy in women with ITP is generally good, if close monitoring and treatment is provided to expectant mothers and infants [41]. One woman gave the following anecdote that was characteristic of other reports: "When I first got ITP I thought that I couldn't have children. And then my gynecologist told me that I could have children while taking prednisone. All those years my hematologist made me think I couldn't have children."

\section{Discussion}

The clinical manifestations of ITP and its management affect patients' everyday activities and well-being. Our research aimed to propose a conceptual model that describes the impact of ITP and its treatments on patients' HRQoL by using information gathered from the published literature and from the patient perspective reported in focus groups. Qualitative methods were used to group the patient reports into one biological variable, two main determinants, and five conceptual domains of HRQoL relevant to patients with ITP.

A conceptual model providing a proposed causal linkage with HRQoL can be useful for several reasons. To begin, it 
helps to further explore the disease area and proposes a pathway for how benefits and risks of new treatments may impact the lives of ITP patients. Also this pathway will assist researchers in selecting (or developing) appropriate outcome measures to evaluate a treatment's efficacy.

Although the etiology of ITP is poorly understood, patients with low platelet counts are at greater risk of complications. Also, platelet counts, with or without the presence of symptoms, can dictate whether to treat ITP. It is to be expected, then, that in the focus groups, patients reported keen awareness and close monitoring of the ups and downs of their platelet counts. The emphasis placed on the fluctuations in this clinical marker appears to cause nearly as much anxiety for the patient as the actual disease symptoms, particularly for patients that have undergone splenectomy with the hope of full permanent remission. Further, the focus group patients reported some distress about the confusion surrounding the disease, specifically with relation to childbearing. Future efforts to educate those affected by the disease could reduce the discrepancy between the perceptions and the medical facts.

Symptoms of the disease were found to be important factors characterizing patient well-being. According to patients, the bruising and bleeding resulting from ITP significantly worsen HRQoL. In addition, since fatigue substantially hindered patients' ability to perform their daily activities, the management of fatigue could potentially improve overall HRQoL. However, despite our finding that over $90 \%$ of the patients in the CA and OK focus groups mentioned fatigue, currently fatigue is not sufficiently often considered by clinicians who manage persons with ITP. In fact, fatigue is seldom recorded as an adverse event in clinical trials of ITP patients.

In addition to potentially severe clinical outcomes, the effects of the various ITP treatments impact multiple facets of the patients' lives. However, the adverse effects of corticosteroids, such as weight gain and mood swings, were most emphasized during the focus group discussions. Patients reported side effects of other treatments, such as hair loss and susceptibility to infection, less frequently. Since treatment with corticosteroids is usually first-line therapy for patients with ITP, it is likely that all patients in the focus groups had received treatment with corticosteroids at some time.

Patients reported some concern over increased susceptibility to infection as a result of splenectomy. These reported fears may seem unfounded when reviewing some reports of high success rates (i.e., increased platelet counts) one year following splenectomy $[21,26]$. However, some evidence suggests that longer-term outcomes may not be as favorable bringing to question the risk-ben- efit ratio of splenectomy in the face of all the anxiety. Kojouri, et al. found that $66 \%$ of the patients had a complete response to splenectomy, defined as achievement and maintenance of a normal platelet count, $\left(>150 \times 10^{9} /\right.$ L or as defined in the original report and $>100 \times 10^{9} / \mathrm{L}$ for all measurements 30 days or longer after splenectomy, and with no additional treatment for ITP, except for the tapering of perioperative glucocorticoids or other treatments) with a median follow-up of 29 months. They also found surgical complication rates of $12.9 \%$ and $9.6 \%$ for laparotomy and laparoscopic splenectomy, respectively. However, they acknowledge that the follow-up duration may not have been long enough to provide a valid assessment of long-term risks associated with splenectomy, especially since relapse rates increase with duration of follow up [13]. Portielje, et al. found that, of those patients who had experienced complete response (platelet count $>100 \times 10^{9} / \mathrm{L}$ ) within 2 years of diagnosis, $45 \%$ had experienced at least one ITP-related hospital admission in the 10-year follow-up period [49]. McMillan and Durette studied 105 chronic ITP adults who were refractory to splenectomy. During the median follow-up period of 110 months, 6 patients $(5.6 \%)$ died of treatment-related complications (including sepsis associated with long periods of immunosuppression, postoperative pancreatitis, and transfusion-related hepatitis C) [23].

It is worth noting that just as the model provides a pathway for describing how negative outcomes or adverse events of treatment affect the patients' HRQoL; the model also holds in the case of positive effects of treatment. Although it was not emphasized explicitly in the focus groups, any effects of a particular treatment that patients perceive as positive (e.g., a stable platelet count, increase in energy and vitality, decrease in anxiety) would likely improve the domains of HRQoL.

ITP researchers have acknowledged the value that PRO measures would bring to understanding the signs and symptoms of ITP and its treatments effects on HRQoL. After conducting a literature review aimed at assessing variability and terminology used in the diagnosis and treatment of ITP, Ruggeri, et al. suggested that further studies consider the effect of treatment options on quality of life evaluations as well as treatment effects on platelet counts [54]. Bussel, et al. also recognized that improved treatment outcomes with new treatments can have an effect on patient HRQoL [34]. Our literature searches yielded only four instances in which a questionnaire was used to assess quality of life $[17,32,56,57]$. The PRO endpoints pursued in the studies were consistent with the concerns voiced by the patients in the focus groups, e.g. fear of bleeding and extreme fatigue. 
A multi-dimensional measure of HRQoL in ITP can be particularly useful when comparing HRQoL outcomes of treatments that may have differential impacts on HRQoL or when some aspects of HRQoL may be improved at the expense of others. Our proposed conceptual model delineates concepts that may be considered in a PRO questionnaire to assess HRQoL changes in persons with ITP. Most of these concepts are included in the ITP-PAQ; any differences between the model and the ITP-PAQ reflect that the questionnaire was developed for use in clinical trials and could not contain all issues that may be relevant to patients. The model will also assist in the selection of items, scales, and/or questionnaires that may be appropriate to utilize when assessing HRQoL in ITP patients.

This research has some limitations. For one, the conceptual model focuses specifically on the relationship between symptoms, side-effects, and HRQoL and did not address other concepts such as treatment satisfaction, treatment decision-making, and medication compliance. Research looking into the roles of these other outcomes on patient HRQoL in ITP may be important.

The decision to use focus groups to gather patient contributions also created limitations. For instance, only English-speaking patients in the US were sampled; therefore the conceptual model may need further testing to be generalizable in other populations. The time commitment required for focus group participation and the use of an honorarium as an incentive for participating may have introduced a self-selection bias into the sample population. Also, the entry criteria for participation in the focus groups were very broad. No strata were used to guarantee a distribution in severity of disease, success of treatment, duration of disease, or age. All patients were recruited by physicians from tertiary care centers that tend to treat more severe or refractory patients. Therefore, this sample may be biased by over representing patients that are, in general, more ill or more aware of their illness. It is worth noting that although group interaction can stimulate participant ideas that might not have been available on an individual basis, it may also lead to overemphasis of the opinions of the groups' participants. For this reason, it is critical to the success of a focus group to have a highly experienced moderator guide the discussion.

Finally, because we could not match demographic or clinical history to individual focus group participants, it was not possible to distinguish whether the concepts affected some patients more than others. In particular, gender and age may play an important role in determining the HRQoL of adult patients living with chronic ITP. Further studies on the varying severity and progress of ITP may lead to slightly different conclusions regarding the pathway from platelet counts through signs and symptoms and HRQoL domains to overall HRQoL. However, the intent of this research was to develop a broad conceptual model.

Future research will build on the findings of this study. The sample size needed for qualitative research is determined by the concept of theoretical saturation. In order to achieve saturation, data must be collected until no new information is obtained. For this model our empirical data source, the existing transcripts of contributions from 23 patients, was not designed to reach saturation of themes or concepts. Researchers may wish to collect additional patient data either in focus groups or individual interviews to reach saturation on all areas of interest.

While the literature searches yielded several questionnaires that have been used to assess HRQoL in persons with ITP, only the ITP-PAQ, developed based on the feedback from these very focus groups of ITP patients, was designed and validated in patients with ITP. The ITP-PAQ covers many of the themes identified in our conceptual model for ITP, however other concepts important to patients, e.g. ability to perform daily activities, feelings of social isolation, inability to travel, financial stress, and reduction in libido, are not included in the ITP-PAQ. Patient-reported data captured with questionnaires such as the ITP-PAQ may be used to refine the conceptual model presented here. We expect further targeted research, in the style of Moore, et al. [60], to be used to test the relationships proposed in the ITP conceptual model, e.g., observing the changes in HRQoL of a subset of patients with a specific treatment or patients with a specific symptom.

\section{Conclusion}

A conceptual model of health-related quality of life for patients with ITP consisting of two main determinants was developed: (1) signs and symptoms; and, (2) treatment effects; and five HRQoL domains: (1) emotional health, (2) functional health, (3) work life, (4) social and leisure activities, and (5) reproductive health. This conceptual model should help to inform the evaluation of therapeutic strategies for ITP.

\section{Competing interests}

The analysis of focus group transcripts, interpretation of results, conceptual model design, and the writing of the manuscript represent the joint collaboration of all authors of this study, which was funded solely by Amgen, Inc, Thousand Oaks, California, USA. No other additional funding for this study was provided. The decision to submit this manuscript for publication was subject to the approval of Amgen, Inc. and all authors. 
SDM is the President of Health Outcomes Solution. SKG and JLN are employees of Amgen, Inc. KLM is an employee of ICON Clinical Research Lifecycle Sciences Group. DC is employed by Northwestern University Medical School. CS is employed by John Hopkins University, School of Medicine. CS' contribution to this publication was as a paid consultant to Amgen. AW is employed by John Hopkins University, Bloomberg School of Public Health. RT is an employee of Phase V Technologies. JBB is an employee of Weill Cornell Medical Center. JNG is an employee by the University of Oklahoma Health Sciences Center. RM is a Professor Emeritus of the Scripps Research Institute. DKW is an employee of the University of Nebraska at Kearney.

\section{Authors' contributions}

SDM supervised the interpretation of the results from the focus groups and conceptual model development activities and assisted in the drafting of the manuscript. KLM reviewed the focus group transcripts and participated in the drafting the manuscript. JBB, JNG, RM, and JLN provided clinical expertise in the design and execution of the focus groups and in the drafting of the clinical aspects of the manuscript. DC, CS, RT, and AW provided outcomes expertise in the development of the conceptual model and participated in the drafting of the manuscript. DKW provided her expertise in the design, execution, and moderating of the focus groups, and in the review of the manuscript. SKG assisted in interpreting the results and drafting the manuscript. All authors contributed to the development of the manuscript. All authors read and approved the final manuscript.

\section{Acknowledgements}

The authors thank Jennifer Welle, of ICON Clinical Research Lifecycle Sciences Group and Shana B Traina, formerly of Amgen, Inc. for their help in the preparation of this manuscript.

\section{References}

I. Cines DB, Blanchette VS: Immune thrombocytopenic purpura. The New England journal of medicine 2002, 346(I3):995-1008.

2. George JN: Management of patients with refractory immune thrombocytopenic purpura. J Thromb Haemost 2006, 4(8): I664- I672.

3. Harrington WJ, Minnich V, Hollingsworth JW, Moore CV: Demonstration of a thrombocytopenic factor in the blood of patients with thrombocytopenic purpura. J Lab Clin Med I95I, 38(I): $1-10$.

4. George JN: Diagnosis, clinical course, and management of idiopathic thrombocytopenic purpura. Curr Opin Hematol 1996, 3(5):335-340.

5. Kaye JA, Schoonen M, Fryzek J: ITP incidence and mortality in UK General Practice Research Database (GPRD): Vienna, Austria. ; 2007.

6. Burden of illness of idiopathic thrombocytopenic purpura (ITP) - an overview . Cerner Health Insights, Editor 2004: I-7I.

7. Cohen YC, Djulbegovic B, Shamai-Lubovitz O, Mozes B: The bleeding risk and natural history of idiopathic thrombocytopenic purpura in patients with persistent low platelet counts. Arch Intern Med 2000, I60( I I): 1630-1638.
8. McMillan R: Therapy for adults with refractory chronic immune thrombocytopenic purpura. Ann Intern Med 1997, I 26(4):307-3|4.

9. Wong GC, Lee LH: A study of idiopathic thrombocytopenic purpura (ITP) patients over a ten-year period. Ann Acad Med Singapore 1998, 27(6):789-793.

10. George JN: Treatment options for chronic idiopathic (immune) thrombocytopenic purpura. Seminars in hematology 2000, 37(I Suppl I):3 I-34.

II. George JN, el-Harake MA, Raskob GE: Chronic idiopathic thrombocytopenic purpura. The New England journal of medicine 1994, 33 I (I8): | 207-|2|I.

12. Aledort LM, Lyons RM, Okano G, Levenque J: Restrospective Matched Cohort Study of Immune Thrombocytopenic Purpura (ITP): Complications Related to Corticosteroid (CS) Use: Orlando, Florida. ; 2006.

13. Kojouri K, Vesely SK, Terrell DR, George JN: Splenectomy for adult patients with idiopathic thrombocytopenic purpura: a systematic review to assess long-term platelet count responses, prediction of response, and surgical complications. Blood 2004, I 04(9):2623-2634.

14. Braendstrup P, Bjerrum OW, Nielsen OJ, Jensen BA, Clausen NT, Hansen PB, Andersen I, Schmidt K, Andersen TM, Peterslund NA, Birgens HS, Plesner T, Pedersen BB, Hasselbalch HC: Rituximab chimeric anti-CD20 monoclonal antibody treatment for adult refractory idiopathic thrombocytopenic purpura. American Journal of Hematology 2005, 78(4):275-280.

15. U.S. Food and Drug Administration: Draft - Guidance for Industry Patient-Reported Outcome Measures: Use in Medical Product Development to Support Labeling Claims. Rockville, MD , U.S. Department of Health and Human Services; 2006.

16. Committee for Medicinal Products for Human Use: Reflection Paper on the Regulatotory Guidance for the Use of HealthRelated Quality of Life (HRQL) Measures in the Evaluation of Medicinal Products . London , European Medicines Agency; 2005.

17. Mathias SD, Bussel JB, George JN, McMillan R, Okano GJ, Nichol JL: A disease-specific measure of health-related quality of life for use in adults with immune thrombocytopenic purpura: its development and validation. Health and quality of life outcomes 2007, 5:II.

18. Mathias SD, Bussel JB, George JN, McMillan R, Okano GJ, Nichol JL: A disease-specific measure of health-related quality of life in adults with chronic immune thrombocytopenic purpura: psychometric testing in an open-label clinical trial. Clinical therapeutics 2007, 29(5):950-962.

19. Wilson IB, Cleary PD: Linking clinical variables with healthrelated quality of life. A conceptual model of patient outcomes. JAMA 1995, 273(I):59-65.

20. Finfgeld-Connett D: Qualitative concept development: implications for nursing research and knowledge. Nursing forum 2006, 4 I (3): $103-112$.

2I. Andres E, Zimmer J, Noel E, Kaltenbach G, Koumarianou A, Maloisel F: Idiopathic thrombocytopenic purpura: a retrospective analysis in 139 patients of the influence of age on the response to corticosteroids, splenectomy and danazol. Drugs Aging 2003, 20(I I):84 I-846.

22. Sandler SG, Novak SC, Roland B: The cost of treating immune thrombocytopenic purpura using intravenous $\mathbf{R h}$ immune globulin versus intravenous immune globulin. American Journal of Hematology 2000, 63(3): I56-158.

23. McMillan R, Durette C: Long-term outcomes in adults with chronic ITP after splenectomy failure. Blood 2004, I 04(4):956-960.

24. Cordera F, Long KH, Nagorney DM, McMurtry EK, Schleck C, Ilstrup $D$, Donohue JH: Open versus laparoscopic splenectomy for idiopathic thrombocytopenic purpura: clinical and economic analysis. Surgery 2003, I34(I):45-52.

25. Lozano-Salazar RR, Herrera MF, Vargas-Vorackova F, Lopez-Karpovitch $X$ : Laparoscopic versus open splenectomy for immune thrombocytopenic purpura. Am J Surg I998, I 76(4):366-369.

26. Tsereteli Z, Smith CD, Branum GD, Galloway JR, Amerson RJ, Chakaraborty $H$, Hunter JG: Are the favorable outcomes of splenectomy predictable inpatients with idiopathic thrombocytopenic purpura (ITP)? Surg Endosc 200I, I 5(1 2): I 386-I389. 
27. Delaitre B, Blezel E, Samama G, Barrat C, Gossot D, Bresler L, Meyer C, Heyd B, Collet D, Champault G: Laparoscopic splenectomy for idiopathic thrombocytopenic purpura. Surg Laparosc Endosc Percutan Tech 2002, I 2(6):4I 2-4I9.

28. Ojima H, Kato T, Araki K, Okamura K, Manda R, Hirayama I, Hosouchi $\mathrm{Y}$, Nishida $\mathrm{Y}$, Kuwano $\mathrm{H}$ : Factors predicting long-term responses to splenectomy in patients with idiopathic thrombocytopenic purpura. World J Surg 2006, 30(4):553-559.

29. Watson DI, Coventry BJ, Chin T, Gill PG, Malycha P: Laparoscopic versus open splenectomy for immune thrombocytopenic purpura. Surgery 1997, I 2 I(I): 18-22.

30. Kang CM, Lee JG, Kim KS, Choi JS, Lee WJ, Kim BR: What we learned from the experience of laparoscopic splenectomy in patients with idiopathic thrombocytopenic purpura (ITP)-single surgeon experiences. Surg Laparosc Endosc Percutan Tech 2006, I6(3):15I-155.

3I. Khan LR, Nixon S): Laparoscopic splenectomy is a better treatment for adult ITP than steroids--it should be used earlier in patient management. Conclusions of a ten-year follow-up study. Surgeon 2007, 5(I):3-4, 6-8

32. Cooper N, Woloski BM, Fodero EM, Novoa M, Leber M, Beer JH, Bussel JB: Does treatment with intermittent infusions of intravenous anti-D allow a proportion of adults with recently diagnosed immune thrombocytopenic purpura to avoid splenectomy? Blood 2002, 99(6): I922-1927.

33. Bennett CL, Weinberg PD, Golub RM, Bussel JB: The potential for treatment of idiopathic thrombocytopenic purpura with anti-D to prevent splenectomy: a predictive cost analysis. Seminars in hematology 2000, 37(I SuppI I):26-30.

34. Bussel JB, Eldor A, Kelton JG, Varon D, Brenner B, Gillis S, Angiolillo A, Kulkarni R, Abshire TC, Kelleher J: IGIV-C, a novel intravenous immunoglobulin: evaluation of safety, efficacy, mechanisms of action, and impact on quality of life. Thromb Haemost 2004, 9I(4):77|-778.

35. McMinn JR Jr., Cohen S, Moore J, Lilly S, Parkhurst J, Tarantino MD, Terrell DR, George JN: Complete recovery from refractory immune thrombocytopenic purpura in three patients treated with etanercept. American Journal of Hematology 2003, 73(2): $135-140$.

36. McMillan R: Long-term outcomes after treatment for refractory immune thrombocytopenic purpura. The New England journal of medicine 200I, 344(I 8): | 402-1403.

37. Bussel JB: Splenectomy-sparing strategies for the treatment and long-term maintenance of chronic idiopathic (immune) thrombocytopenic purpura. Seminars in hematology 2000, 37(I SuppI I): I-4.

38. Kahn MJ, McCrae KR: Splenectomy in immune thrombocytopenic purpura: recent controversies and long-term outcomes. Curr Hematol Rep 2004, 3(5):3 I7-323.

39. Sandler SG: The spleen and splenectomy in immune (idiopathic) thrombocytopenic purpura. Seminars in hematology 2000, 37(I SuppI I): I0-12.

40. Sandler SG, Tutuncuoglu SO: Immune thrombocytopenic purpura - current management practices. Expert Opin Pharmacother 2004, 5( I 2):25I 5-2527.

4l. Suri V, Aggarwal N, Saxena S, Malhotra P, Varma S: Maternal and perinatal outcome in idiopathic thrombocytopenic purpura (ITP) with pregnancy. Acta Obstet Gynecol Scand 2006, 85(I 2): | 430-| 435.

42. Borna S, Borna H, Khazardoost S: Maternal and neonatal outcomes in pregnant women with immune thrombocytopenic purpura. Arch Iran Med 2006, 9(2): I I5-II8.

43. Webert KE, Mittal R, Sigouin C, Heddle NM, Kelton JG: A retrospective I I-year analysis of obstetric patients with idiopathic thrombocytopenic purpura. Blood 2003, I 02(I3):4306-43 II.

44. Devendra K, Koh LP: Pregnancy in women with idiopathic thrombocytopaenic purpura. Ann Acad Med Singapore 2002, 3I(3):276-280.

45. Ali R, Ozkalemkas F, Ozcelik T, Ozkocaman V, Ozan U, Kimya Y, Koksal N, Bulbul-Baskan E, Develioglu O, Tufekci M, Tunali A: Idiopathic thrombocytopenic purpura in pregnancy: a single institutional experience with maternal and neonatal outcomes. Ann Hematol 2003, 82(6):348-352.

46. lyori $\mathrm{H}$, Fujisawa $\mathrm{K}$, Akatsuka J: Thrombocytopenia in neonates born to women with autoimmune thrombocytopenic purpura. Pediatr Hematol Oncol 1997, 14(4):367-373.
47. Parnas M, Sheiner E, Shoham-Vardi I, Burstein E, Yermiahu T, Levi I, Holcberg G, Yerushalmi R: Moderate to severe thrombocytopenia during pregnancy. Eur J Obstet Gynecol Reprod Biol 2006, I 28 (I2):163-168.

48. Salawu L, Durosinmi MA: Immune thrombocytopaenic purpura: I I-year experience in Ile-Ife, Nigeria. Afr J Med Med Sci 200I, 30(I-2):99-103.

49. Portielje JE, Westendorp RG, Kluin-Nelemans HC, Brand A: Morbidity and mortality in adults with idiopathic thrombocytopenic purpura. Blood 200I, 97(9):2549-2554.

50. Frederiksen $\mathrm{H}$, Schmidt $\mathrm{K}$ : The incidence of idiopathic thrombocytopenic purpura in adults increases with age. Blood 1999, 94(3):909-9|3.

5I. Simpson KN, Coughlin CM, Eron J, Bussel JB: Idiopathic thrombocytopenia purpura: Treatment patterns and an analysis of cost associated with intravenous immunoglobulin and anti-D therapy. Seminars in hematology 1998, 35(I Suppl I):58-64.

52. Cooper $\mathrm{N}$, Bussel $\mathrm{J}$ : The pathogenesis of immune thrombocytopaenic purpura. BrJ Haematol 2006, 133(4):364-374.

53. Vesely SK, Perdue J], Rizvi MA, Terrell DR, George JN: Management of adult patients with persistent idiopathic thrombocytopenic purpura following splenectomy: a systematic review. Ann Intern Med 2004, I 40(2): I I2-I20.

54. Ruggeri M, Fortuna S, Rodeghiero F: Heterogeneity of terminology and clinical definitions in adult idiopathic thrombocytopenic purpura: a critical appraisal from literature analysis. Pediatr Blood Cancer 2006, 47(5 Suppl):653-656.

55. Matzdorff A, Arnold G: Treatment of chronic immune thrombocytopenic purpura: the patients' perspective. Eur J Haematol 2007, 78(5):38I-388.

56. Zhou Z, Yang L, Chen Z, Chen X, Guo Y, Wang X, Dong X, Wang T, Zhang L, Qiu Z, Yang R: Health-related quality of life measured by the Short Form 36 in immune thrombocytopenic purpura: a cross-sectional survey in China. Eur J Haematol 2007, 78(6):5|8-523.

57. McMillan R, Bussel JB, George JN, Lalla D, Nichol JL: Self-reported health-related quality of life in adults with chronic immune thrombocytopenic purpura. American Journal of Hematology 2007, 83(2): $150-4$.

58. Provan D, Newland A: Fifty years of idiopathic thrombocytopenic purpura (ITP): management of refractory ITP in adults. Br J Haematol 2002, I I 8(4):933-944.

59. Cines DB, James BB: How I treat idiopathic thrombocytopenic purpura (ITP). Blood 2005, 106(7):2244-2250.

60. Moore M, Hofer S, McGee H, Ring L: Can the concepts of depression and quality of life be integrated using a time perspective? Health and quality of life outcomes 2005, 3:1.

Publish with Bio Med Central and every scientist can read your work free of charge

"BioMed Central will be the most significant development for disseminating the results of biomedical research in our lifetime. "

Sir Paul Nurse, Cancer Research UK

Your research papers will be:

- available free of charge to the entire biomedical community

- peer reviewed and published immediately upon acceptance

- cited in PubMed and archived on PubMed Central

- yours - you keep the copyright
BioMedcentral 